\title{
Inhibitory effect of streptococci on the growth of $M$. catarrhalis strains and the diversity of putative bacteriocin-like gene loci in the genomes of $S$. pneumoniae and its relatives
}

\author{
L. N. Ikryannikova ${ }^{\text {*}}$ (D, M. V. Malakhova' , G. G. Lominadze², I. Yu. Karpova', E. S. Kostryukova ${ }^{1}$, N. A. Mayansky ${ }^{2,3}$, \\ A. N. Kruglov', E. A. Klimova ${ }^{5}$, E. S. Lisitsina ${ }^{6}$, E. N. Ilina ${ }^{1}$ and V. M. Govorun
}

\begin{abstract}
S. pneumoniae is a facultative human pathogen causing a wide range of infections including the life-threatening pneumoniae or meningitis. It colonizes nasopharynx as well as its closest phylogenetic relatives S. pseudopneumoniae and S. mitis. Both the latter, despite the considerable morphological and phenotypic similarity with the pneumococcus, are considerably less pathogenic for humans and cause infections mainly in the immunocompromized hosts. In this work, we compared the inhibitory effect of S. pneumoniae and its relatives on the growth of Moraxella catarrhalis strains using the culture-based antagonistic test. We observed that the inhibitory effect of $S$. mitis strains is kept when a hydrogen peroxide produced by cells is inactivated by catalase, and even when the live cells are killed in chloroform vapors, in contrast to the pneumococcus whose inhibiting ability disappeared when the cells die. It was suggested that this effect may be due to the production of bacterial antimicrobial peptides by S. mitis, so we examined the genomes of our strains for the presence of bacteriocin-like peptides encoding genes. We observed that a set of bacteriocin-like genes in the genome of S. mitis is greatly poorer in comparison with S. pneumoniae one; moreover, in one S. mitis strain we found no bacteriocin-like genes. It could mean that there are probably some additional opportunities of S. mitis to inhibit the growth of competing neighbors which are still have to be discovered.
\end{abstract}

Keywords: Viridans group streptococci, S. pneumoniae and its relatives, M. catarrhalis growth inhibition, Bacteriocinassociated gene loci

\section{Introduction}

S. pneumoniae is a facultative pathogen causing a wide range of infections in children and adults, often with fatal outcome (van der Poll and Opal 2009; Donkor 2013). It colonizes human nasopharynx and can further migrate through the Eustachian tubes to cause otitis media, descend the respiratory tract to cause pneumonia or invade the bloodstream through the respiratory epithelium to cause bacteremia and meningitis, or spontaneously disappear over time (Shak et al. 2013).

\footnotetext{
*Correspondence: Larisa.Ikryannikova@gmail.com

${ }^{1}$ Federal Research and Clinical Center of Physical-Chemical Medicine,

Malaya Pirogovskaya str., 1a, Moscow 119435, Russia

Full list of author information is available at the end of the article
}

Along with S. pneumoniae, other streptococcal species including the closest phylogenetic relatives of pneumococci-S. pseudopneumoniae and S. mitis-are common residents of nasopharynx. Despite the considerable morphological and phenotypic similarity, which often prevents the correct identification and differentiation of these three species, they are very different in degrees of injuriousness to humans: while S. pneumoniae is associated with life-threatening diseases (pneumoniae or meningitis), S. mitis is a commensal causing infections mainly in the immunocompromized hosts (Teles et al. 2011; Mitchell 2011; Kilian et al. 2008). A special place belongs to $S$. pseudopneumoniae, whose pathogenic potential is still controversial (Harf-Monteil et al. 2006; 
Keith et al. 2006; Keith and Murdoch 2008; Fuursted et al. 2016). A lot of efforts were expended to explain the significant differences in pathogenicity between pneumococci and their genetic relatives. It was shown that the S. mitis genome contains homologues for many pneumococcal virulence factors involved in colonization and adherence including genes of surface proteins HtrA, ZmpB and PavA, choline-binding proteins LytB, LytC, $\mathrm{CbpD}$ and $\mathrm{CbpE}$, lipoprotein SlrA etc., whereas some of them like the hyaluronidase gene hysA, ply, and lyt $A$ are absent (Denapaite et al. 2010). Also, in S. mitis, the virulence gene repertoire may vary from strain to strain. The current concept postulates that the full virulence factor arsenal is required to overcome the human immune defense as successfully as S. pneumoniae does (Mitchell 2011; Doern and Burnham 2010; Whatmore et al. 2000).

Pneumococcus and its relatives are not the only inhabitants of the nasopharynx. In accordance with the some investigations, more than 600 bacterial species can reside in the oral cavity-gateway into the upper respiratory tract (Dewhirst et al. 2010). The most common bacterial families besides Streptococcaceae were found Moraxellaceae, Corynebacteriaceae, Pasteurellaceae (including the genus Haemophilus) and Staphylococcaceae (Shak et al. 2013; Pettigrew et al. 2008), which colonize nasopharynx for the first months of life. Generally, a composition of the upper respiratory tract microbiome varies greatly among individuals and over time. It is influenced by many factors such as the host genetic background, age, social status, antibiotic use, vaccination, season, smoking etc. Among other factors, one of the most important is the interaction between microbes, including competitive one (Pettigrew et al. 2008; Bosch et al. 2013; Chen et al. 2015). In this work, we tried to evaluate and compare the competitive potential of S. pneumoniae and its closest commensal relatives (S. pseudopneumoniae and $S$. mitis) against Moraxella catarrhalis strains using both the traditional culture-based antagonistic tests and in silico searching of the genes encoding putative antimicrobial peptides across the genomes of the study strains. In our view, the results of this study can be valuable in terms of the competition inside the microbial community may impact nasopharyngeal dynamics and carriage of pathogenic or potential pathogenic bacteria. Therefore, an understanding of features of microbe-microbe interactions in the upper respiratory tract could provide not only the better insight into the pathogenesis of respiratory diseases, but maybe new tools to manage a microbial community for the human.

\section{Materials and methods}

\section{Strains and their identification}

Nine clinical isolates of viridans group streptococci were provided by the different clinical agencies of Moscow. Two S. pneumoniae isolates (Spn_357 and Spn_2009) were kindly provided by the A.I. Evdokimov Moscow State University of Medicine and Dentistry, and they were collected from the patients diagnosed with a sepsis or purulent meningitis. Two unencapsulated or non-typeable (NT) S. pneumoniae (Spn-NT_13856 and Spn-NT_2298) as well as two S. pseudopneumoniae (Spspn_G42 and Spspn_22725) isolates were acquired from the nasopharynx of paediatric patients of the Moscow Scientific Centre of Children Health, who were hospitalized with the different diagnosis, and three $S$. mitis isolates (Sm_11/5, Sm_13/39 and Sm_18/56) have been obtained from the Moscow National Agency for Clinical Pharmacology and Pharmacy. All isolates were routinely characterized by the standard viridans group streptococci identification tests under acquisition.

Being transferred to our laboratory, isolates were streaked out on the plates of Columbia agar (Oxoid Ltd., UK) supplied with a $5 \%$ of sheep blood, to form isolated single colonies; pure cultures were subcultured from single colonies after the overnight incubation at $37^{\circ} \mathrm{C}$ in air with $5 \% \mathrm{CO}_{2}$. All strains were re-tested: the optochin (OPT) susceptibility and bile solubility tests were made using the standard diagnostic optochin or sodium deoxycholate discs (Research Centrum on Pharmacotherapy, St. Petersburg, Russia) respectively, in accordance with the manufacturer's instructions. The latex agglutination assay was accomplished by using of "Slidex ${ }^{\circledR}$ pneumo-kit" (bioMerieux $^{\circledR}$, France).

Main features of strains under study are presented in Table 1. Two strains, Spn_357 and Spn_2009, were "ordinary" pneumococci demonstrating the expected reactions for all routine identification tests. They were susceptible to OPT and sodium deoxycholate ("bile"), and agglutinated with the latex particles in "Slidex" pneumo-kit" assay. Multilocus sequence analysis (MLSA) attributed both isolates to the $S$. pneumoniae group. Two other S. pneumoniae strains, Spn-NT_13856 and Spn-NT_2298, were not "ordinary" pneumococci. These strains were unencapsulated, or non-typeable (NT), and they demonstrated negative reactions in latex agglutination and bile solubility tests; one strain, Spn-NT_13856, was resistant to OPT. Nevertheless, both strains appeared in the pneumococcal cluster by MLSA and had sequence type ST2996, as MLST procedure showed. This ST was firstly assigned to a strain selected in 2006 in Arkhangelsk (Russia) and belongs to a large clonal family of the NT pneumococci (http://pubmlst.org/spneumoniae). These 
Table 1 Characterization of study strains

\begin{tabular}{|c|c|c|c|c|c|c|c|c|}
\hline \multirow{2}{*}{$\begin{array}{l}\text { Strain ID } \\
\text { (VKM }{ }^{\mathrm{a}} \text { ID) }\end{array}$} & \multirow[t]{2}{*}{ Species } & \multirow{2}{*}{$\begin{array}{l}\text { Provider } / \text { iso- } \\
\text { lation year }\end{array}$} & \multirow{2}{*}{$\begin{array}{l}\text { Isolate source/ } \\
\text { patient age }\end{array}$} & \multicolumn{5}{|l|}{ Identification } \\
\hline & & & & $\begin{array}{l}\text { OPT test }\left(\mathrm{CO}_{2}\right. \\
\text { atm.) }\end{array}$ & Bile solubility & $\begin{array}{l}\text { Latex agglu- } \\
\text { tination test } \\
\text { ("Slidex } \\
\text { pneumo-kit") }\end{array}$ & Serotype $^{d}$ & $\begin{array}{l}\text { Sequence type } \\
\text { (MLST) }\end{array}$ \\
\hline $\begin{array}{l}\text { Spn_357 } \\
\text { (VKM B-3128) }\end{array}$ & S. pneumoniae & EMSUMD/2008 & $\begin{array}{l}\text { Cerebrospinal } \\
\text { fluid/adu }\end{array}$ & pos. & pos. & pos. & $23 \mathrm{~F}$ & ST 81 \\
\hline $\begin{array}{l}\text { Spn_2009 } \\
\text { (VKM B-3127) }\end{array}$ & S. pneumoniae & EMSUMD/2008 & Blood/n.d. & pos. & pos. & pos. & $22 \mathrm{~F} / \mathrm{A}$ & ST 1470 \\
\hline $\begin{array}{l}\text { Spn-NT_13856 } \\
\text { (VKM B-3125) }\end{array}$ & S. pneumoniae & $\mathrm{SCCH} / 2013$ & $\begin{array}{l}\text { Nasopharynx/ } \\
\text { ped }\end{array}$ & neg. & neg. & neg. & $N T^{b}$ & ST 2996 \\
\hline $\begin{array}{l}\text { Spn-NT_2298 } \\
\text { (VKM B-3126) }\end{array}$ & S.pneumoniae & $\mathrm{SCCH} / 2013$ & $\begin{array}{l}\text { Nasopharynx/ } \\
\text { ped }\end{array}$ & pos. & neg. & neg. & NT & ST 2996 \\
\hline $\begin{array}{l}\text { Spspn_G42 } \\
\text { (VKM B-3123) }\end{array}$ & $\begin{array}{l}\text { S. pseudopneu- } \\
\text { moniae }\end{array}$ & $\mathrm{SCCH} / 2013$ & $\begin{array}{l}\text { Nasopharynx/ } \\
\text { ped }\end{array}$ & neg. ${ }^{c}$ & neg. & neg. & - & - \\
\hline $\begin{array}{l}\text { Spspn_22725 } \\
\text { (VKM B-3124) }\end{array}$ & $\begin{array}{l}\text { S. pseudopneu- } \\
\text { moniae }\end{array}$ & $\mathrm{SCCH} / 2013$ & $\begin{array}{l}\text { Nasopharynx/ } \\
\text { ped }\end{array}$ & neg. ${ }^{c}$ & neg. & neg. & - & - \\
\hline $\begin{array}{l}\text { Sm_11/5 } \\
\text { (VKM B-3130) }\end{array}$ & S. mitis & NACPP/2009 & $\begin{array}{l}\text { Nasopharynx/ } \\
\text { adu }\end{array}$ & neg. & neg. & neg. & - & - \\
\hline $\begin{array}{l}\text { Sm_13/39 } \\
\text { (VKM B-3131) }\end{array}$ & S. mitis & NACPP/2009 & $\begin{array}{l}\text { Nasopharynx/ } \\
\text { ped }\end{array}$ & neg. & neg. & neg. & - & - \\
\hline $\begin{array}{l}\text { Sm_18/56 } \\
\text { (VKM B-3129) }\end{array}$ & S. mitis & NACPP/2009 & $\begin{array}{l}\text { Nasopharynx/ } \\
\text { adu }\end{array}$ & neg. & neg. & neg. & - & - \\
\hline
\end{tabular}

pos. positive, neg. negative, n.d. no data, adu adult, ped pediatric, NT non-typeable

a VKM is all-Russian collection of microorganisms (http://www.vkm.ru/) in which all strains under study are deposited

b EMSUMD-A.I. Evdokimov Moscow State University of Medicine and Dentistry, Moscow, Russia; SCCH—Federal State Budgetary Inst. “Scientific Center of Children Health" of RAMS, Moscow, Russia; NACPP—National Agency for Clinical Pharmacology and Pharmacy, Moscow, Russia

c Some zones of inhibition (less than $14 \mathrm{~mm}$ ) near OPT discs were observed for these strains under culturing in $\mathrm{CO}_{2}$ atmosphere, in contrast to culturing in air, where zones of inhibition were $18-20 \mathrm{~mm}$ and more

d Serotypes of pneumococcal strains were determined by inspection of the nucleotide sequences of genes coding the fragments of capsules, in accordance with the CDC recommendation (http://www.cdc.gov/streplab/protocols.html) (see "Materials and methods")

interesting strains have been discussed in more details in (Ikryannikova et al. 2016).

Two S. pseudopneumoniae strains were initially attributed to the mitis group non-pneumococci by routine identification tests. However, in contrast to S. mitis strains, these pseudopneumococci reproducibly demonstrated clear 8-10 $\mathrm{mm}$ inhibition zones around the OPT discs being cultivated in $5 \% \mathrm{CO}_{2}$ atmosphere. According to (A decree of the Ministry of Public Health of Russian Federation 1985), these strains should be referred to as OPT-nonsusceptible. However, in the ambient atmosphere, both strains were susceptible to OPT (inhibition zone $>14 \mathrm{~mm}$ ). MLSA analysis unambiguously assigned these strains to the S. pseudopneumoniae cluster.

Strains have been kept in the laboratory strains bank at $-70{ }^{\circ} \mathrm{C}$ in Brain Heart Infusion broth (BD, USA) supplemented with $30 \%$ of fetal bovine serum (Gibco, USA) and $20 \%$ of glycerol. Also, all strains were deposited into the all-Russian collection of microorganisms (http://www. vkm.ru/) and available on request (see strains VKM identifiers in Table 1).
Moraxella catarrhalis strains (Mc51, Mc76 and Mc49) were provided from the LTD Scientific and Industrial Company "Lytech".

\section{DNA extraction}

For all genetic manipulations, total streptococcal DNA was extracted using the modified protocol of Miller et al. (1988). Briefly, $18 \mathrm{~h}$ culture from two blood agar plates was harvested and lysed in the Promega Nuclei Lysis Solution buffer (Promega, USA). After that, the cellular proteins were removed by adding of the saturated $\mathrm{NaCl}$ solution, and the genomic DNA was concentrated and desalted by isopropanol precipitation. Final DNA pellet was re-suspended in 50-100 $\mu \mathrm{l}$ of TE buffer and kept at $4{ }^{\circ} \mathrm{C}$. For whole genome sequencing, DNA was additionally purified by using of minicolumns for DNA purification ("Technoclon", Russia), in accordance with the manufacturer's instructions.

\section{Genetic identification: MLST and MLSA schemes}

Multilocus sequence typing and MLSA were performed as described by Enright and Spratt (1998) and by Bishop 
et al. (2009) respectively, with minor modifications for MLSA scheme described earlier in (Ikryannikova et al. 2011). Results were analyzed using the MLST (http:// www.mlst.net) and MLSA (http://viridans.emlsa.net/) databases. Vector NTI 9.0 and MEGA 6.0 software was used for the manipulations with gene fragments and phylogenetic evolutionary analysis.

Multilocus sequence analysis and MLST gene fragments were repeatedly inspected when getting the whole genome nucleotide sequences of strains (see below). Looking for the MLSA or MLST genes in whole genome nucleotide sequences of the strains under study was realized using of the BLAST v. 2.2.23+ software.

\section{Assay for the growth inhibitors production}

Screening for the production of inhibitory agents was based on a dual-layer agar plate technique. The bottom layer consisted of $10 \mathrm{ml}$ of 1.5\% LB broth agar (Amresco, USA) on which the inhibitor-producing test strain grew, and the top layer consisted of $6 \mathrm{ml}$ of soft $0.7 \%$ agar (Helicon, Russia) containing $1 \%$ tryptone, $0.5 \%$ yeast extract (Oxoid Ltd., UK) and $0.1 \% \mathrm{NaCl}$, to support the growth of the indicator strain ( $M$. catarrhalis). To screen for inhibitory effect, $18 \mathrm{~h}$ test strains grown on the Columbia blood agar (Oxoid Ltd., UK) plates were stabbed into the bottom LB broth agar layer and incubated for $18 \mathrm{~h}$ at $37{ }^{\circ} \mathrm{C}$ in air with $5 \% \mathrm{CO}_{2}$. In some cases, LB broth agar surfaces were treated with catalase (4000 or 10,000 units per plate) before stabbing of the test strain. Indicator strains were cultured on the Columbia blood agar plates. Cells were harvested by the $10 \mu \mathrm{l}$ microbiological loop and suspended in $300 \mu \mathrm{l}$ of Brain Heart Infusion broth (BD, USA) to $1 \mathrm{MF}$, and then $100 \mu \mathrm{l}$ of the indicator strain culture was added to the $6 \mathrm{ml}$ of the soft agar and gently stirred. The bottom agar layer stabbed by the test strains was subsequently overlaid with a thin layer of a soft agar containing the indicator strain. Dual-layer plates were further incubated at $37^{\circ} \mathrm{C}$ in air with $5 \% \mathrm{CO}_{2}$. When necessary, the bottom agar layer supporting the growth of the test strains was kept in chloroform vapors for $15 \mathrm{~min}$ and then overlaid with a soft agar containing the indicator strain. Finally, zones of growth inhibition of indicator strain by test strains were inspected after the $10 \mathrm{~h}$ of growth.

\section{Whole genome sequencing and assembly}

Whole genome nucleotide sequences of two strains (Spn-NT_2298 and Spn_22725) were obtained by using the Roche 454 Life Sciences Genome Sequencer FLX+ Genetic Analyzer (Roche 454 Life Science, USA), in accordance with the manufacturer's instructions. Other strains were sequenced by using of the Ion Torrent PGM Genetic Analyzer (Life Technologies, USA). Details of sequencing are given in Additional file 1: Table S1. Genomes were assembled by GS De Novo Assembler v. 2.8 (Roche, USA). Assembly data were annotated using the RAST (Rapid Annotation using Subsystem Technology, USA http://rast.nmpdr.org/) and NCBI (American National Center for Biotechnology Information) PGAP (Prokaryotic Genome Annotation Pipeline, USA, http:// www.ncbi.nlm.nih.gov/genome/annotation_prok/) Annotation Servers, and published in the GenBank database of the NCBI under Accession Numbers listed in Additional file 1: Table S1.

\section{Drawing of whole genome data for the analysis of the bacteriocin production associated clusters and getting of the additional information of strains}

For the looking of genes encoding the potential bacteriocins in the genomes of strains under study, the open webresource BAGEL3 (http://bagel.molgenrug.nl/index.php/ bagel3) (de Jong et al. 2010) was used. BAGEL3 is one of the most significant world databases of bacteriocin-like peptides; this resource have a search tool allowing to identify putative bacteriocins on the basis of conserved domains, physical properties and the presence of biosynthesis, transport and immunity genes in their genomic context. Additionally, we have utilized the results of the investigations of Majchrzykiewicz (2011) whose work on the study of bacteriocin associated loci in S. pneumoniae genome seems to be most detailed.

Looking for the fragments of capsule operon in the genomes of the strains under study was performed using of the BLAST v. 2.2.23+ software. Investigation of the nucleotide sequences of genes coding the fragments of capsules was used to determine the serotypes of $S$. pneumoniae strains, in accordance with the CDC recommendation (http://www.cdc.gov/streplab/protocols. html).

\section{Results}

Inhibitory effect of streptococci on the growth of Moraxella catarrhalis

In the cases when the bottom agar layer stabbed with the test strains was not treated with catalase, we have observed very extensive, often merging zones of $M$. catarrhalis strains growth inhibition. Six test strains stabbed uniformly across the agar surface of 9-mm Petri dish completely inhibited the growth of indicator strains. Treatment of the agar surface with catalase (4000 or 10,000 units per plate) lead to a drastic decrease of the inhibition zones (Table 2). Catalase treatment followed by killing of live bacterial cells in chloroform vapors lead to the complete suppression of the inhibitory effects of pneumococci and pseudopneumococci, but no of $S$. mitis strains (Table 2). 
Table 2 Inhibitory effect of streptococci under study on the growth of $M$. catarrhalis strains

\begin{tabular}{|c|c|c|c|c|}
\hline & \multicolumn{4}{|c|}{ Size of zones of the inhibition of $M$. catarrhalis str. 51 growth by streptococci, $\mathrm{mm}^{\mathrm{a}}$} \\
\hline & + catalase (4000 units/plate) & $\begin{array}{l}\text { + catalase (4000 units/plate) } \\
\text { + chloroform }\end{array}$ & $\begin{array}{l}+ \text { catalase }(10,000 \text { units } \\
\text { plate) }\end{array}$ & $\begin{array}{l}\text { + catalase }(10,000 \text { units } / \\
\text { plate }) \\
+ \text { chloroform }\end{array}$ \\
\hline \multicolumn{5}{|l|}{ Test strains } \\
\hline \multicolumn{5}{|l|}{ S.pneumoniae } \\
\hline Spn_357 & $5 / 6^{b}$ & $0 / 0$ & 2 & 0 \\
\hline Spn_2009 & $9 / 10$ & $0 / 0$ & 10 & 0 \\
\hline \multicolumn{5}{|l|}{ NTS. pneumoniae } \\
\hline Spn-NT_13856 & $3 / 8$ & $0 / 0$ & 2 & 0 \\
\hline Spn-NT_2298 & $8 / 5$ & $0 / 0$ & 4 & 0 \\
\hline \multicolumn{5}{|c|}{ S. pseudopneumoniae } \\
\hline Spspn_G42 & $3 / 2$ & $0 / 0$ & 4 & 0 \\
\hline Spspn_22725 & $3 / 5$ & $0 / 0$ & 2 & 0 \\
\hline \multicolumn{5}{|l|}{ S. mitis } \\
\hline Sm_11/5 & $2 / 5$ & 9 & 5 & 7 \\
\hline Sm_13/39 & $3 / 5$ & 5 & 4 & 6 \\
\hline Sm_18/56 & $7 / 12$ & 6 & 7 & 7 \\
\hline
\end{tabular}

a In the cases when the bottom agar layer stabbed with the test strains was not treated with catalase, we have observed very extensive, often merging zones of $M$. catarrhalis strains growth inhibition, or no growth of the indicator strain at all

b Slash marks the repeat of experiments

\section{Comparative screening of gene clusters associated with bacteriocin production in VGS strains of the mitis group \\ blp and cibAB loci}

In accordance with the data collected for S. pneumoniae and its related species, there are at least two gene clusters associated with the bacteriocin production: blp (bacteriocin-like peptides; earlier $p n c$ or spi) operon and cibAB (competence induced bacteriocins) cluster. Both are well described (see Ref. Lux et al. 2007; Son et al. 2011; Kjos et al. 2016; Miller et al. 2016; Bogaardt et al. 2015), although the confusion in names and the location of constituent genes, due to their complex structure, still occurs.

The reconstruction of $b l p$ cluster in genomes of our strains is given in Fig. 1a. This locus was similar in all pneumococci and pseudopneumococci having an intact regulatory part and BIR consisting of a different number of bacteriocins- and immunity proteins coding genes. Spn_2009 was the exception missing almost all BIR (Bacteriocin Immunity Region) genes. Notably, comparing to S. pneumoniae strains, pseudopneumococci possessed a significantly smaller number of bacteriocin coding genes inside the BIR region.

In S. mitis genomes, blp cluster was also present, although it was substantially different from S. pneumoniae one. The $S$. mitis blp cluster conserved the regulatory $b l p R H$ system genes, while the $b l p C$ pheromone encoding gene as well as the $\mathrm{ABC}$ transporter genes were lost. Two of three $S$. mitis genomes contained no bacteriocin coding genes inside of the BIR region, although there were genes coding putative immune proteins.

Two-peptide class II CibAB bacteriocin is presumably the part of fratricidal killing pathway (Guiral et al. 2005). It was shown for $S$. pneumoniae that when becoming competent streptococcal cells produce a set of factors triggering the lysis of clonal but non-competent relatives. This mechanism is named fratricide, and CibAB bacteriocin was found to be one of the effectors of this process. $c i b A B$ cluster was presented in all pneumococcal and pseudopneumococcal genomes under study, but was not found in two of three $S$. mitis genomes (Fig. 1b). Note that the $c i b C$ gene downstream of $c i b A B$ was missed in the annotations and was deduced by analyses of the corresponding nucleotide sequences, based on the nucleotide sequence of $S$. mitis B6 cibC gene (smi_1957). Thus, the $c i b A B$ bacteriocin cluster did not appear to be specific for S. pneumoniae, opposing an earlier suggestion (Majchrzykiewicz 2011).

Our next step was to search for genes coding potential bacteriocin peptides in the genomes of strains under study using BAGEL3 web-resource.

\section{Lantibiotic clusters}

Besides of the class II bacteriocins, different species of the genus Streptococcus may produce class I posttranslationally modified peptides termed lantibiotics (Nes et al. 2007; Hakenbeck and Chhatwal 2007). In 


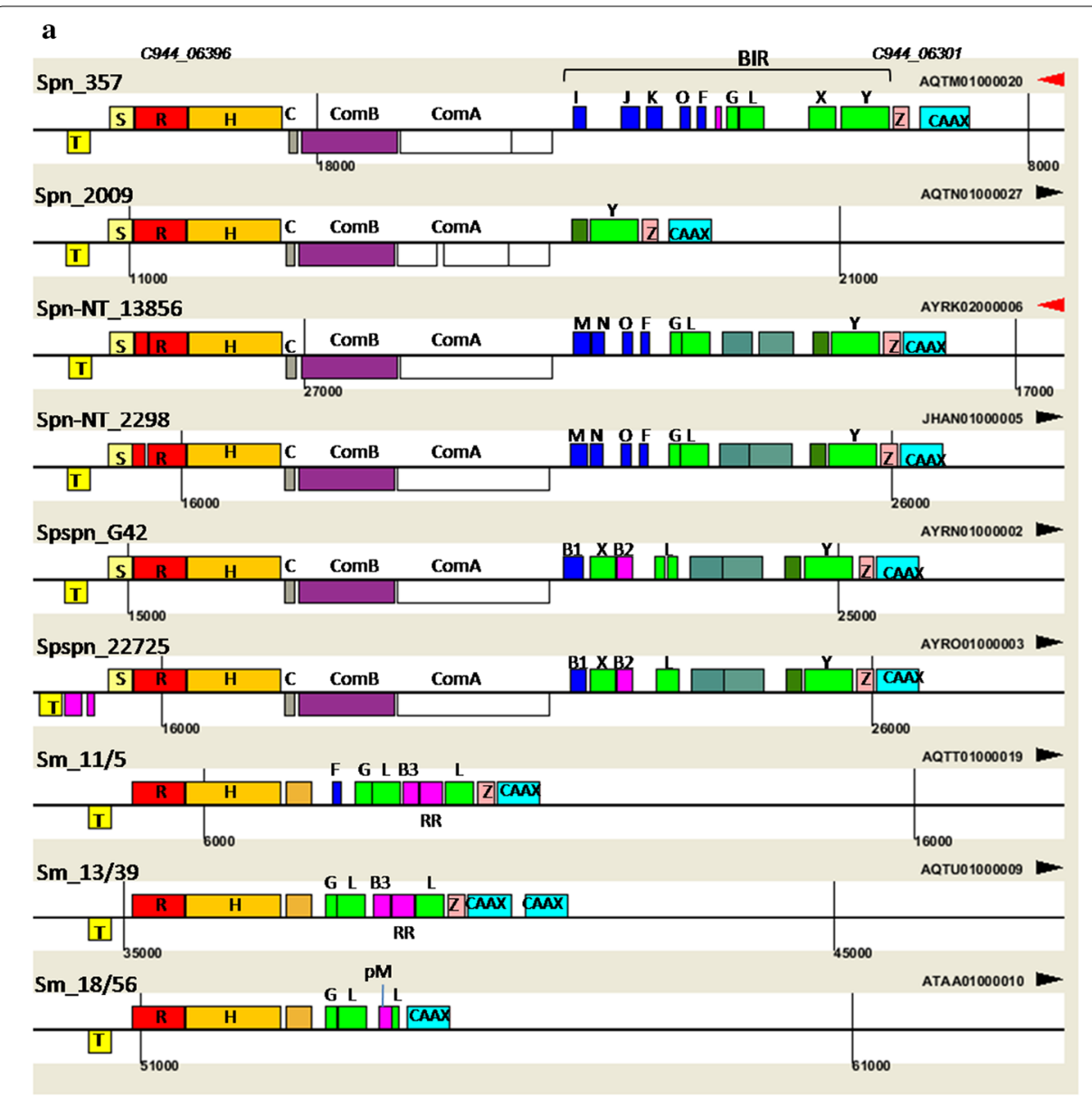

$\square$ BlpTprotein, fusion

LytR family transcriptional regulator, BIpS

Response regulator of the LytR/AlgR family, BlpR

sensor histidine kinase $\mathrm{BlpH}$

$\square$ peptide pheromone BlpC

$\square$ BlpCABC transporter (ComB)

ABC transporter ATP-binding protein BIpA

$\square$ Cation transport ATPase

Bacteriocin-like peptide

Bacteriocin immunity protein

thioredoxin

Predicted cell-wall-anchored protein SasA (LPXTG motif)

pncw

$\square$ BlpZ protein, fusion

$\square$ CAAX protease

$\square$ hypothetical protein

T-BlpT, S-BlpS, R-BlpR, H-BlpH; C-pheromon BlpC;

I, J, K, M, N, O-bacteriocin-like peptides Blpl, BlpJ, BlpK, BlpM, BlpN, Blpo, respectively; Z-BIpZ;

$L, X, Y$ - bacteriocin immunity proteins BlpL, BlpX, BlpY, respectively;

F-pncF, putative bacteriocin (Lux, 2007);

G, PM - pncG and pncM, putative

immunity proteins (Lux, 2007);

B1- bacteriocin_llc superfamily

B2, B3 - hypotetical protein, putative

bacteriocin;

RR - hypothetical protein, putative role in replication.

b
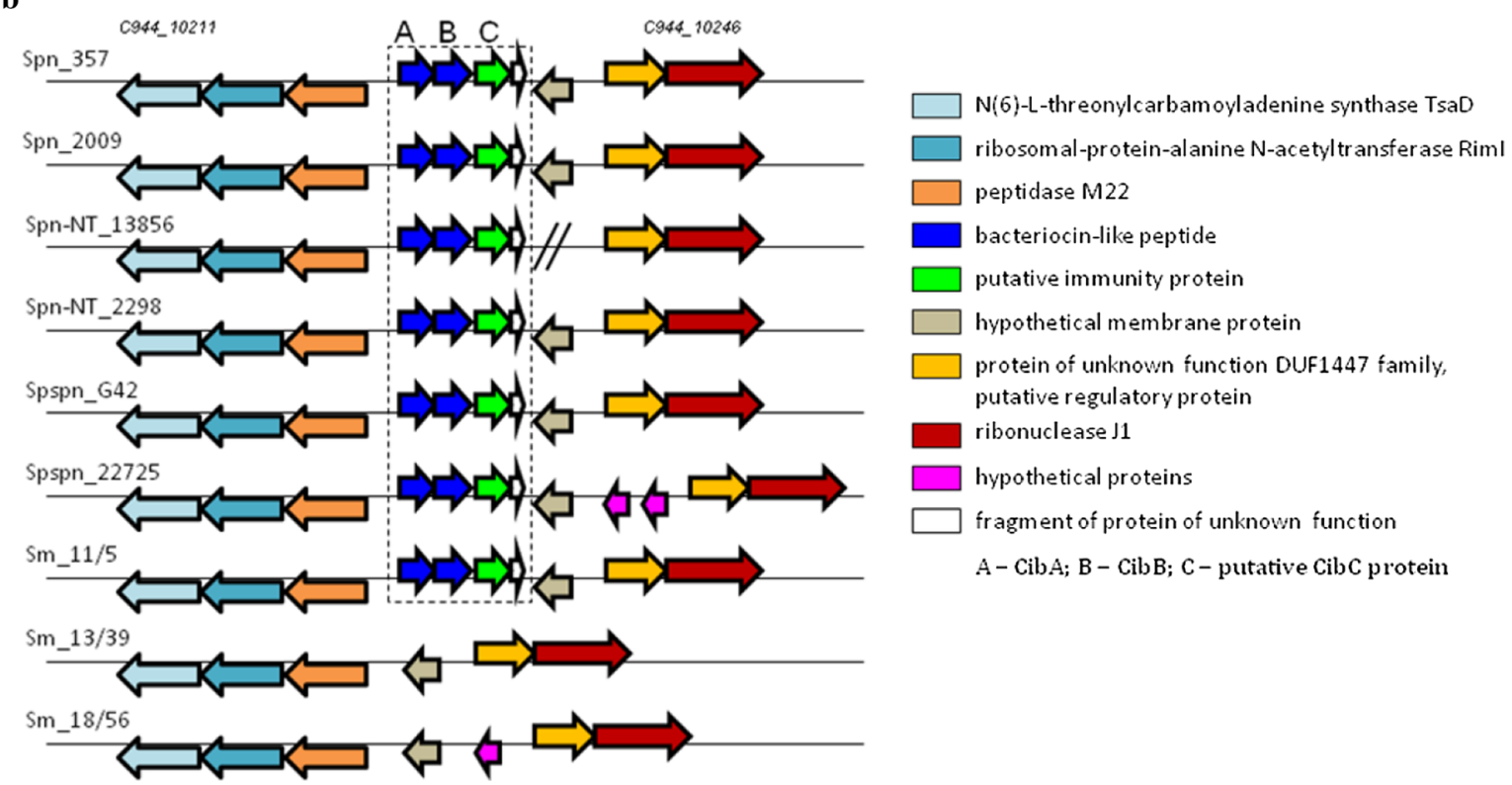

Fig. 1 Reconstruction of blp (a) and cibAB (b) gene cluster structures according to genome analysis of nine VGS strains under study. The upper picture is prepared using of JContextExplorer v. 3.0 program (Seitzer et al. 2013). Homologous genes in compared samples are indicated by the same color (excluding the bacteriocin- and immune protein coding genes in the upper picture). Double slash in the lower picture indicates the gap in the nucleotide sequence of Spn-NT_13856 (a point of joining of two contigs). Here and further: NCBI identifiers of the first and last genes of genome fragments presented are given for Spn_357 
our strains, only one lantibiotic-like peptide coding gene was discovered in the genome of Spn_357: a twopeptide bacteriocin was part of gene cluster (cluster I by Majchrzykiewicz). This cluster included genes encoding putative regulation, modification, transport and immune proteins (Fig. 2a). This cluster was missed in other genomes under study. In Spn_2009, a truncated variant of this cluster was found: modifying and transport genes were lost including bacteriocin genes.
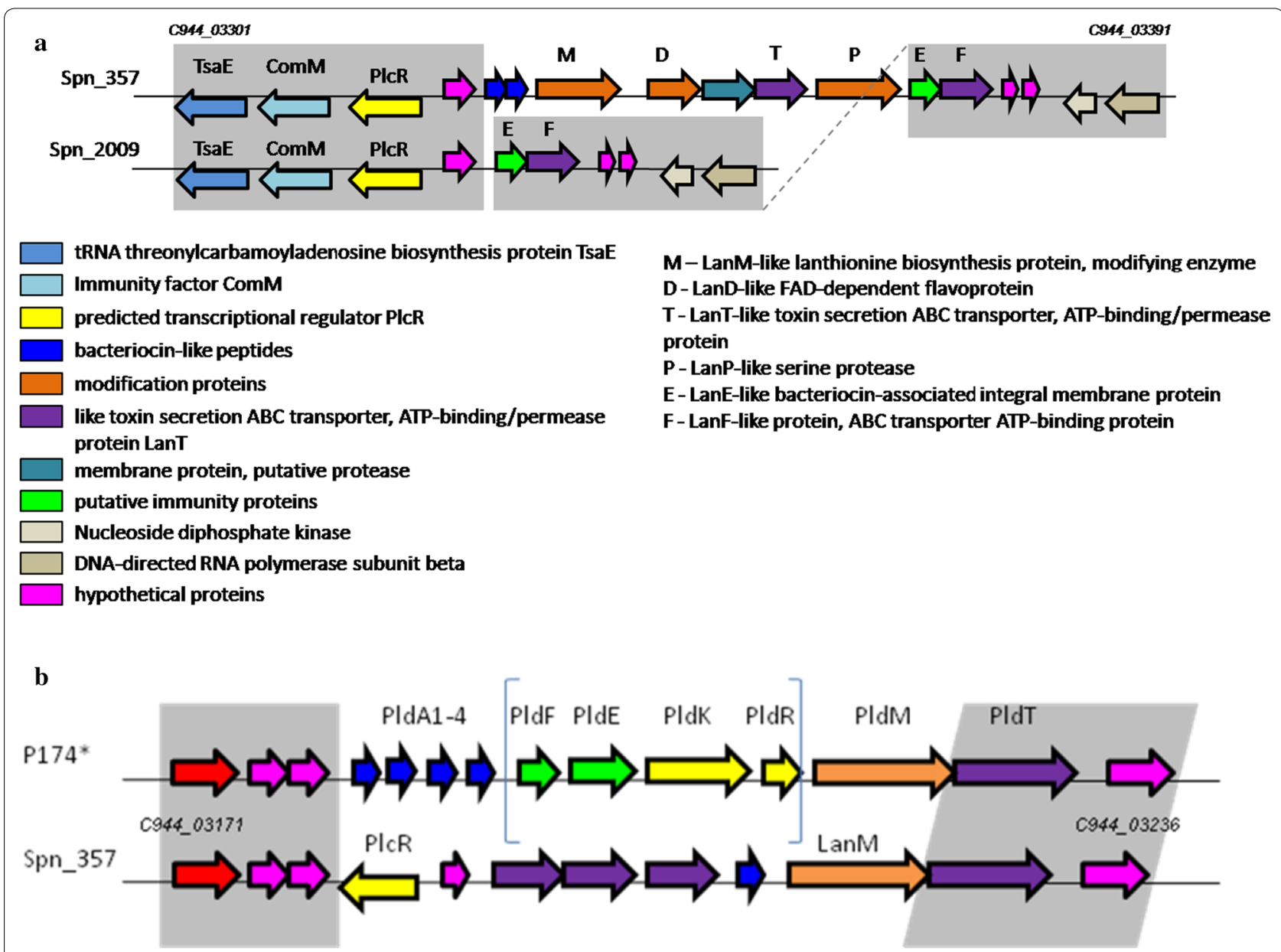

SNF2 family protein; putative conjugative transposon DNA recombination protein regulation function

bacteriocin-like peptide

putative immunity function $\mathrm{ABC}$-type bacteriocin/lantibiotic transporter; putative role in modification and/or immunity modification function hypothetical proteins
$P I C R$ - predicted transcriptional regulator

PId1-4 - putative lantibiotic proteins

PIdF - ABC transporter ATP binding protein, putative role in immunity

PIdE - $A B C$ transporter permease, putative role in immunity

PIdK - histidine kinase

$P I d R$ - DNA-binding response regulator

PIdM - lanthionine synthetase C family protein

PIdT - lantibiotic transporter

LanM - LanM-like protein, lantibiotic synthetase

Fig. 2 Graphic representation of lantibiotic clusters I (a) and pld locus (b) based on the genome analysis of strains under study. *P174 is the strain described in the work (Maricic et al. 2016) where an unusual tandem of four lantibiotic-like genes was found out. Square brackets point a part of the pld locus found in S. mitis strains cluster IV gene locus (see text). Grey fields highlight homologous fragments in different genomes 
One more pneumococcal lantibiotic locus (the pneumolancidin, pld, locus) has been described very recently by Maricic et al. (2016). It is located on a mobile element that has been found in some pneumococcal lineages. A special feature of pld locus is unusual tandem array of four inhibitory peptides, three of which are absolutely required for antibacterial activity (see Fig. 2b). An alternative variant of the lantibiotic locus that was described for S. pneumoniae ATCC 700669 strain (Maricic et al. 2016) includes only one lantibiotic precursor peptide (Fig. 2b). In our strains, the pld locus was found in Spn_357 only having an "ATCC 700669-like" structure (Fig. 2b). We were not able to detect this locus in genomes of other study strains; however, a part of it namely pldFEKR fragment was found in the nearest vicinity of cluster IV in two of three $S$. mitis strains (see below).

\section{Lactococcin 972-like peptides in genomes of strains under study}

Two lactococcin 972-like peptides were detected by BAGEL3 in our strains. Lactococcin 972 is a IIc class bacteriocin obtained from Lactococcus lactis that affects a target cell inhibiting cell division by blocking of septum formation (Alvarez-Sieiro et al. 2016). The corresponding loci in pneumococcal genomes were designated as clusters III and IV by Majchrzykiewicz (2011). Both clusters carry homologous genes, but they are localized in different regions of genomes. Both clusters include a bacteriocin gene, a putative self-immunity protein and $A B C$ transporter downstream. Lactococcin-like genes were discovered within the cluster III in Spn_357 and Spspn 22725 , and within the cluster IV in all genomes except S. mitis ones (Fig. 3). In two S. mitis genomes, the entire cluster was lost, whereas in Sm_11/5 immune and transport genes were preserved, but a structural gene was missed.

It should be noted that upstream of the position of the cluster IV in pneumococcal genomes, in genomes of two of three $S$. mitis strains we detected fragments of the lantibiotic pld operon including genes required for pneumolancidin immunity and regulation (pldFEKR) (Fig. 3b). In accordance with the arrangement of genes in the pld locus, we would expect to find pneumolancidin pldA1-4 genes upstream of pldF. Actually, the nucleotide sequence in this region included two fragments similar to pldA1-3 and pldA4 genes. However, both nucleotide fragments were disrupted by stop codons.

\section{Putative bacteriocin-coding clusters in streptococcal genomes}

Inspired by results of Majchrzykiewicz, we examined two more gene loci presumably related to the bacteriocin production activity. Schemes of these loci are given in Additional file 1: Figure S1. One of them, cluster V or $p p u$ ("pneumococcal peptide of unknown function), was thoroughly studied by Majchrzykiewicz, to understand whether it produces a functional bacteriocin-like peptide, but no antimicrobial activity specifically related to the PpuA bacteriocin-like peptide was revealed. We discovered the $p p u A$ gene in four of nine genomes including pneumococci and pseudopneumococci, but not S. mitis. Other locus (cluster VI by Majchrzykiewicz) comprised of four genes encoding small peptides, putative bacteriocins. However, the function of these peptides as well as bacteriocin-like potential of the whole cluster is still unclear.

\section{Sactipeptide locus in the genome of S. mitis 13/39 strain}

One more bacteriocin-like peptide encoding gene was discovered in the Sm_13/39 genome, which was attributed to the sactipeptides. Sactipeptides represent a subclass of sulfur-bridged bacteriocins which are characterized by a typical pattern comprising three or four cysteine residues separated by a certain number of amino acids (Fig. 4). These cysteine residues serve to form intramolecular thioether bridges between cysteine sulfurs and $\alpha$-carbons of other amino acids within a peptide (Himes et al. 2016). Upstream and downstream of the putative bacteriocin, two radical SAM/SPASM domain-containing proteins are located that presumably mediate posttranslational thioether linkage formation (Lohans and Vederas 2014).

In the remaining studied strains, neither sactipeptide bacteriocin nor adjacent radical SAM enzymes encoding genes were detected.

\section{The "S. mitis" bacteriocin-encoding cluster in streptococcal genomes}

This locus upstream of $\operatorname{com} A B$ was first mentioned in the paper concerning with the analysis of the $S$. mitis B6 genome (11), so we quoted it as "S. mitis" cluster. Later it was also mentioned when describing the S. pseudopneumoniae IS7493 genome (Shahinas et al. 2013). This obscure locus seems to be very variable in different members of the Streptococcus genus. In our pneumococcal strains, it included genes encoding BlpU (BlpO)-like bacteriocin and (except Spn_357) a number of putative membrane proteins of unclear function (Fig. 5). Transcriptional regulator and multidrug transporter encoding genes in this locus of pneumococci and pseudopneumococci were found. Also, a BOX element directly upstream of $\operatorname{com} A B$ was conserved in all species excluding two of three $S$. mitis strains.

In two S. pseudopneumoniae, the arrangement of the "S. mitis" cluster seems to be the most interesting. First, it 


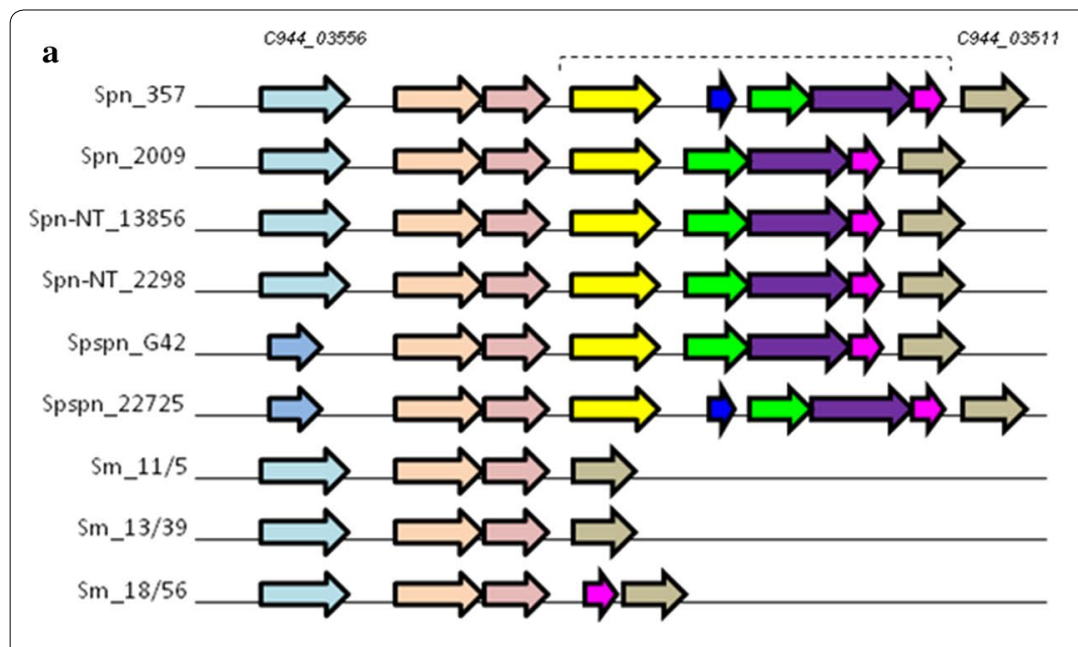

b

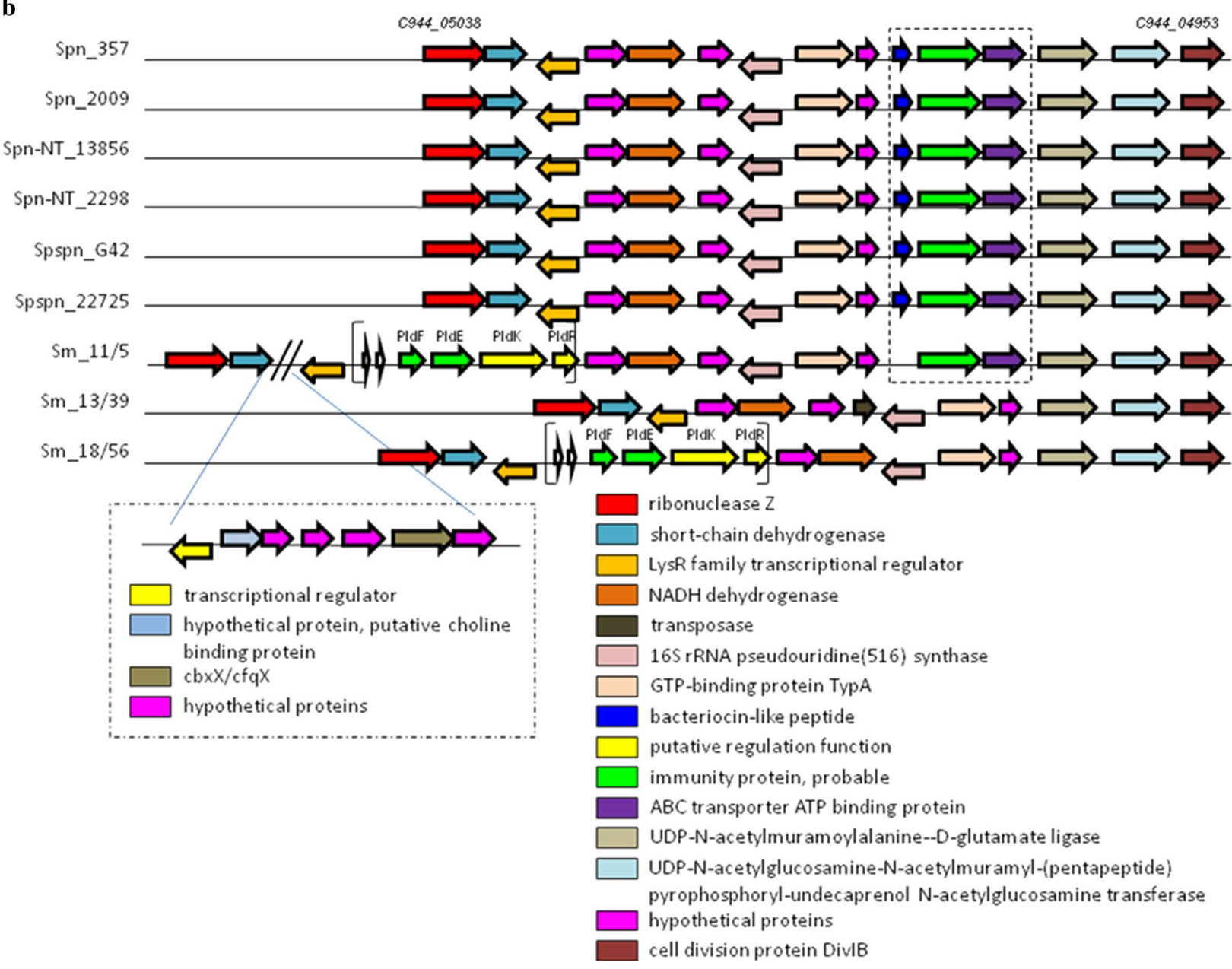

Fig. 3 Graphic representation of lactococcin 972 clusters III (a) and IV (b), respectively. Homologous genes in different samples are indicated by the same color. Square brackets point a part of the pld locus in S. mitis genomes in the bottom picture. Unfilled arrows mark the fragments of nucleotide sequences which are homologous to pld1-3 or pld4 genes (see text) 


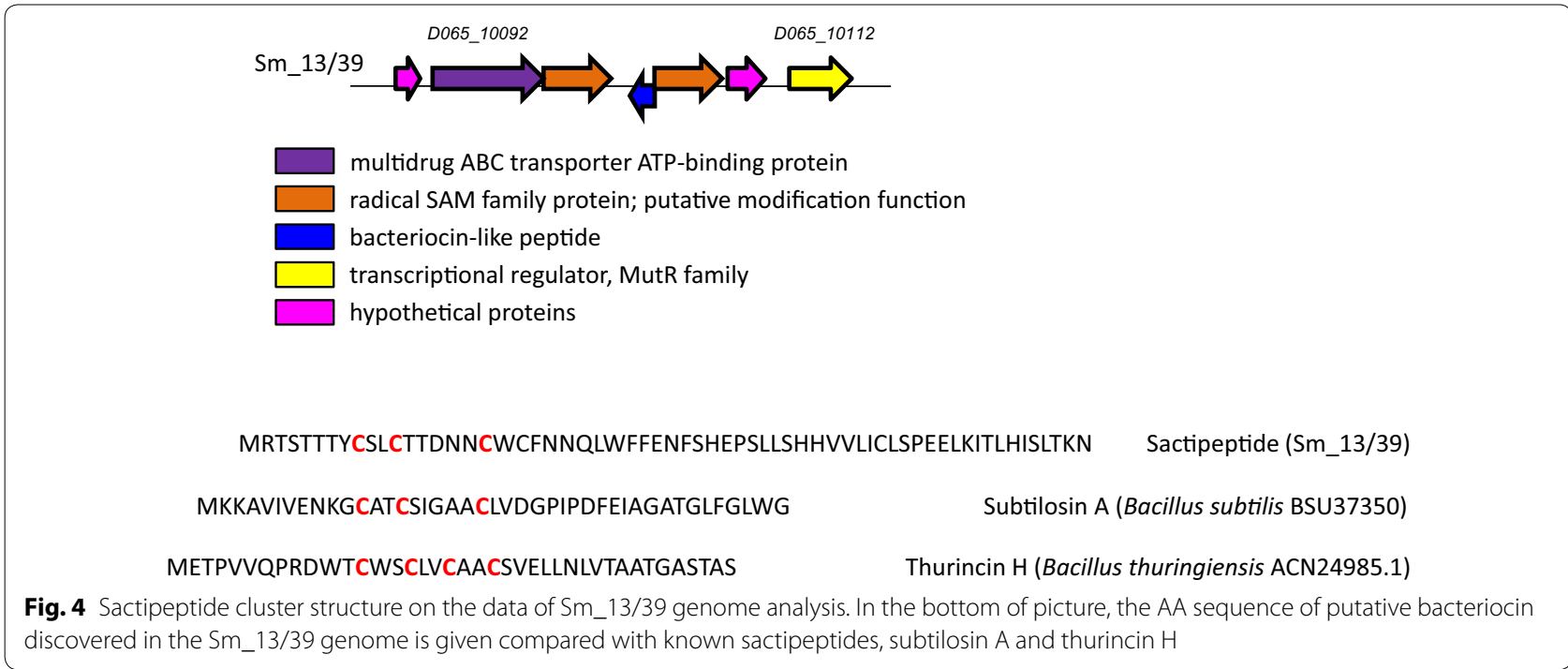

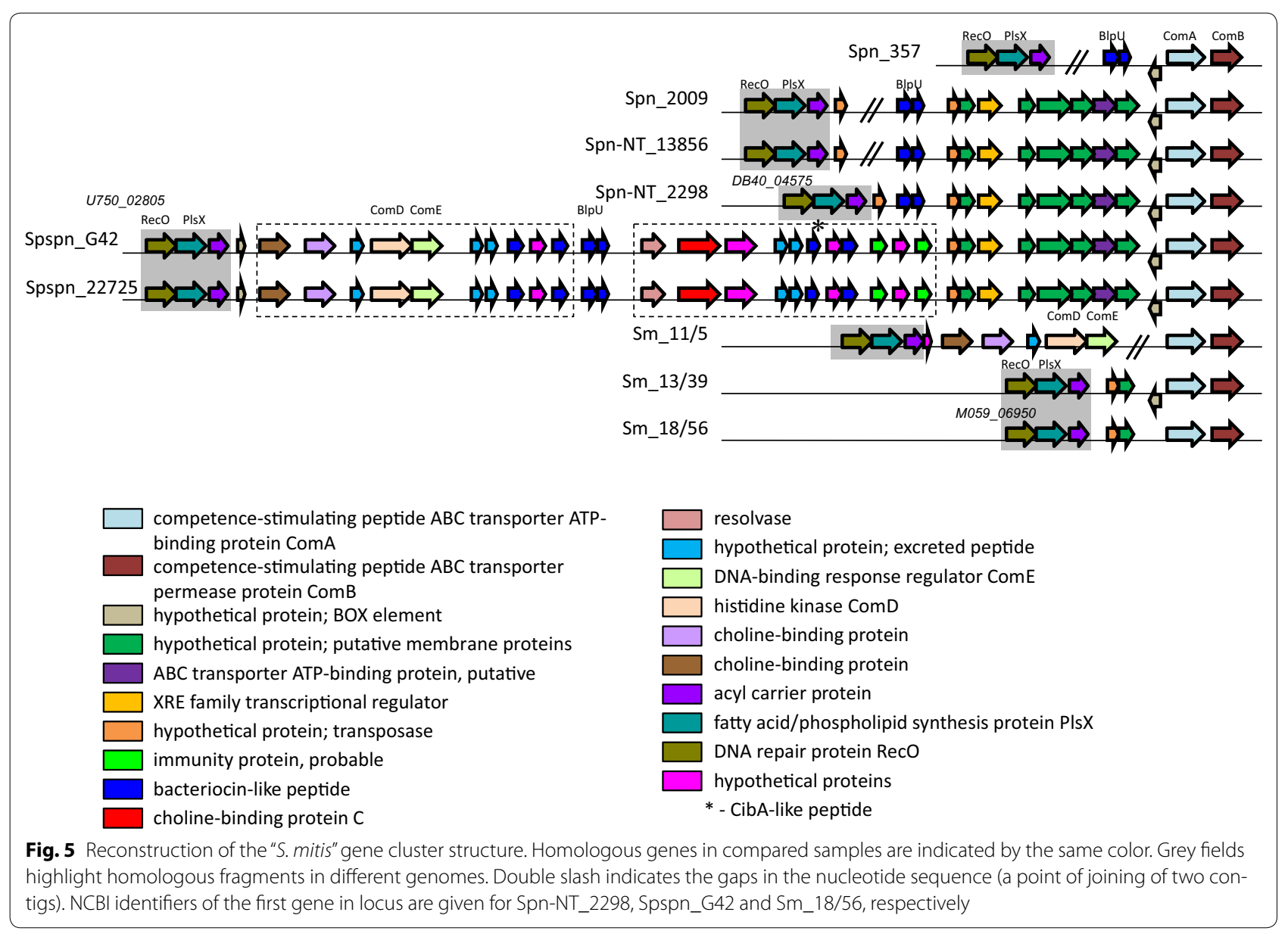

included a fragment of the competence regulon, namely a ComDE-like two-component regulatory system. This system plays a role at the initial stage of competence, when extracellular competence stimulating peptide pheromone (CSP) encoded by the $\operatorname{com} C$ gene is sensed by histidine kinase receptor ComD, which, upon binding of its ligand, 
transfers a phosphoryl group to the response regulator ComE. Phosphorylated ComE drives the expression of early competence genes (Claverys and Havarstein 2007). However, we revealed no homologous of $\operatorname{com} C$ gene in the vicinity of $c o m D E$. Note that we found a competence regulated cibA-like gene at this locus in both pseudopneumococci strains. At the same time, there is a full repertoire of genes of the competence regulon located at the position equivalent to that of the S. pneumoniae genome in both S. pseudopneumoniae strains.

Second, in addition to BlpU, a large number of the putative class II bacteriocin-like peptide encoding genes with a typical GG-processing site were present in this locus. Also, two immune protein encoding genes upstream of the field of putative membrane proteins were discovered. Finally, a few of excreted peptides of unknown function were localized there.

Surprisingly, "S. mitis" cluster was completely lost in two of three S. mitis genomes and truncated in the third one $\left(\mathrm{Sm}_{-} 11 / 5\right)$ that preserved only the regulatory comDE part.

\section{Discussion}

In this study, we investigated an ability of S. pneumoniae and its closest commensal relatives-S. pseudopneumoniae and S. mitis - to inhibit the growth of M. catarrhalis strains. Moraxella catarrhalis have been chosen as indicator strain because it shares the same niche as viridans group streptococci-upper respiratory tract-in a human body (Bosch et al. 2013; Perez et al. 2014), so we might expect a manifestation of established competitive relationships between these species.

Our experiments show some important features. First, VGS streptococci are able to suppress the growth of other microorganism, at that this process is probably mediated substantially by the production of hydrogen peroxide which is inherent for this genus. However, an inhibiting ability is partially kept in all the strains under study even after inactivation of hydrogen peroxide by catalase. At that, the inhibitory effect of both pneumococci and pseudopneumococci on the $M$. catarrhalis strains growth should be probably attributed to the living cells of microorganisms, because of the treatment in chloroform vapors leads to the disappearance of this effect. On the contrary, the inhibiting ability of $S$. mitis strains does not disappear when the bacterial cells are killed in chloroform.

We suggested that this inhibitory effect could be associated with the production of bacterial antimicrobial peptides, so we scanned the genomes of our strains for the presence of appropriate mechanisms for bacteriocins production. Note that this work was not aimed the isolation and characterization of an inhibitory substance, as well as a systematization of all diversity of bacteriocins from streptococcal genomes available from the online databases. We just assumed to identify a basis of the inhibitory ability of strains under study which we observed in the experiments. Also, it seemed interesting to compare "the potential of competitiveness" of pathogen S. pneumoniae and commensals S. pseudopneumoniae and $S$. mitis, because the ability of each of these species to survive inside a competitive microbial community affects the clinically important nasopharyngeal dynamics.

The results that we obtained were rather unexpected. We discovered many opportunities of pneumococci and pseudopneumococci to produce bacteriocins, and first of all it was associated with the presence of the $b l p$ locus which was found intact in all S. pneumoniae and S. pseudopneumoniae. In addition to the $b l p$ operon, there were a number of other loci in the genomes of $S$. pneumoniae and S. pseudopneumoniae which can be associated with a possibility to produce bacteriocins. We can only guess whether all these loci are joined into the complex system, and if so, how this system works, or maybe it is only partially or completely dysfunctional gene clusters that are nothing more than the evolutionary heritage. In any case, all that 'potential of bacteriocinogeny", it seems, was not used by these bacteria in the conditions of our experiment, since the inhibitory effect completely disappeared when the cells were killed in chloroform vapors.

But the most intriguing observation was the finding of significant inhibitory ability of $S$. mitis strains, which was kept even after killing of the test strains in chloroform, in conjunction with a virtually complete lack of bacteriocin-like peptide encoding genes in their genomes. Actually, the "potential of bacteriocinogeny" of S. mitis strains involved into this work inferred on the basis of the analysis of their genomes looks quite poor in comparison with pneumococci and pseudopneumococci. We succeeded to detect two bacteriocin-like peptide encoding genes inside of the blp and cibAB loci of S. mitis Sm_11/5 strain and only one sactipeptide-like encoding gene in the Sm_13/39 strain. No bacteriocin encoding genes were discovered in Sm_18/56 genome. A thorough study of loci, which are presumably associated with bacteriocin production activity in S. pneumoniae, did not clarify the situation with this strain. The significant inhibitory potential of alpha-hemolytic streptococci including $S$. mitis against a variety of Gram-positive and Gram-negative bacteria was observed earlier. The "viridin B", a bacteriocin produced by $S$. mitis and active against Neisseria sicca and coagulase-negative staphylococci, was purified and described in a number of papers almost four decades ago (Law and Dajani 1978; Dajani et al. 1978), but the sequence of this peptide has remained unknown since 
then. This substance was obtained in a cell-free form only after mechanical disruption of bacteriocinogenic cells but has not been isolated from streptococcal culture supernatants (Dajani et al. 1976), so it's hard to speculate what was it in fact. Much later, a broad inhibitory activity of $S$. mitis strains against different microorganisms including S. pyogenes, S. pneumoniae, S. aureus, and B. catarrhalis has been demonstrated again (Santagati et al. 2012). A targeted search for the known streptococcal bacteriocin genes resulted in finding of $s a l A$ or $s b o B$ (encoding lantipeptides salivaricin A or B, respectively) genes in some strains; however, other isolates showing an evident inhibition of the indicator strains did not possess any of these bacteriocin activity determinants.

Thus, the origin of inhibition activity of at least one $S$. mitis strain remains unclear. Perhaps, there is some novel type of antimicrobial peptides in them that has not yet been discovered, or some secreted metabolites which are remained to be identified. In any case, we can see that commensals $S$. mitis are able to compete effectively for their place in the conditions of our experiment, and their competitive tools seem to be different from those of pneumococci.

\section{Additional file}

Additional file 1: Table S1. Details of whole genome sequencing of streptococci strains under study. Figure S1. Graphic representation of putative bacteriocin-associated clusters $\mathrm{V}$ and $\mathrm{VI}$.

\section{Abbreviations}

NT: non-typeable pneumococci; OPT: optochin; MLSA: multilocus sequence analysis; MLST: multilocus sequence typing; ST: sequence type.

\section{Authors' contributions}

LNI - coordination of work, analysis of the results, writing of the manuscript; MVM, ESL — storage and growth of strains, measuring of the inhibitory effect; GGL, NAM, ANK, EAK-acquisition of isolates and their primary characterization; IYK, ESK — whole genomes sequencing, genomes assembly and analysis; ENI-supervision of the work; VMG — head of the Federal Research and Clinical Center of Physical-Chemical Medicine, supervision of project. All authors read and approved the final manuscript.

\section{Author details}

${ }^{1}$ Federal Research and Clinical Center of Physical-Chemical Medicine, Malaya Pirogovskaya str., 1a, Moscow 119435, Russia. ${ }^{2}$ Federal State Budgetary Inst. "Scientific Center of Children Health" of RAMS, Moscow, Russia. ${ }^{3}$ I.M. Sechenov First Moscow State Medical University, Moscow, Russia. ${ }^{4}$ National Agency for Clinical Pharmacology and Pharmacy, Moscow, Russia. ${ }^{5}$ A.l. Evdokimov, Moscow State University of Medicine and Dentistry, Moscow, Russia. ${ }^{6}$ LTD Scientific and Industrial Company "Lytech", Moscow, Russia.

\section{Acknowledgements}

We acknowledge K. Detushev, A.G. Bogun and E.B. Kudryashova for the assistance with a deposition of strains into the collection of microorganisms. We thank A.I. Manolov for the assistance with bioinformatics part of the work. This publication made use the BAGEL3 (http://bagel.molgenrug.nl/index.php/ bagel3), Viridans.eMLSA.net (http://viridans.emlsa.net/) and S. pneumoniae MLST (https://pubmlst.org/spneumoniae/) web-resources.

\section{Competing interests}

The authors declare that they have no competing interests.

\section{Availability of data and materials}

Sequences were deposited in the GenBank database of the NCBI under Accession Numbers CA_000385775.1,GCA_000385795.1, GCA_000506605.2, GCA_000692035.1,GCA_000506665.1,GCA_000506685.1, GCA_000385815.1, GCA_000385835.1,GCA_000430345.1. Strains were deposited into the allRussian collection of microorganisms (http://www.vkm.ru/) and available on request (VKM identifiers VKM B-3123-VKM B-3131).

\section{Consent for publication}

Not applicable.

Ethics approval and consent to participate

Not applicable.

\section{Funding}

This work, including the efforts of L.N. Ikryannikova and M.V. Malakhova, was funded by the Russian Science Foundation (RSF) (Grant Number № 15-15-00158).

\section{Publisher's Note}

Springer Nature remains neutral with regard to jurisdictional claims in published maps and institutional affiliations.

Received: 27 November 2017 Accepted: 5 December 2017

Published online: 13 December 2017

\section{References}

A decree of the Ministry of Public Health of Russian Federation No. 109 « About the unification of microbiologic (bacteriologic) methods in clinical-diagnostic laboratories in hospitals of Russian Federation"—Russian Federation, 22.04.85, n. 535

Alvarez-Sieiro P, Montalbán-López M, Mu D, Kuipers OP (2016) Bacteriocins of lactic acid bacteria: extending the family. Appl Microbiol Biotechnol 100:2939-2951

Bishop CJ, Aanensen DM, Jordan GE, Kilian M, Hanage WP, Spratt BG (2009) Assigning strains to bacterial species via the internet. BMC Biol 7:3

Bogaardt C, van Tonder AJ, Brueggemann AB (2015) Genomic analyses of pneumococci reveal a wide diversity of bacteriocins-including pneumocyclicin, a novel circular bacteriocin. BMC Genom 16:554

Bosch AATM, Biesbroek G, Trzcinski K, Sanders EAM, Bogaert D (2013) Viral and bacterial interactions in the upper respiratory tract. PLoS Pathog 9:e1003057

Chen HX, Lai CH, Hsu HY, Huang JC, Wu HS, Ho MW, Tsai MH, Lin CD (2015) The bacterial interactions in the nasopharynx of children receiving adenoidectomy. BioMedicine 5:39-43

Claverys JP, Havarstein LS (2007) Cannibalism and fratricide: mechanisms and raisons d'être. Nat Rev Microbiol 5:219-229

Dajani AS, Tom MC, Law DJ (1976) Viridins, bacteriocins of alpha-hemolytic streptococci: isolation, characterization, and partial purification. Antimicrob Agents Chemother 9:81-88

Dajani AS, Veres CM, Law DJ (1978) Substances that interfere with action of viridin B, a Streptococcus mitis bacteriocin. Infect Immun 20:20-24

de Jong A, van Heel AJ, Kok J, Kuipers OP (2010) BAGEL2: mining for bacteriocins in genomic data. Nucleic Acids Res 38:W647-W651

Denapaite D, Bruckner R, Nuhn M, Reichmann P, Henrich B, Maurer P, Schahle Y, Selbmann P, Zimmermann W, Wambutt R, Hakenbeck R (2010) The genome of Streptococcus mitis B6-what is a commensal? PLoS ONE 5:e9426

Dewhirst FE, Chen T, Izard J, Paster BJ, Tanner ACR, Yu WH, Lakshmanan A, Wade WG (2010) The human oral microbiome. J Bacteriol 192:5002-5017

Doern CD, Burnham CAD (2010) It's not easy being green: the viridans group streptococci, with a focus on pediatric clinical manifestations. J Clin Microbiol 48:3829-3835 
Donkor ES (2013) Understanding the pneumococcus: transmission and evolution. Front Cell Infect Microbiol 3:1-5

Enright MC, Spratt BG (1998) A multilocus sequence typing scheme for Streptococcus pneumoniae: identification of clones associated with serious invasive disease. Microbiology 144:3049-3060

Fuursted K, Littauer PJ, Greve T, Scholz CFP (2016) Septicemia with Streptococcus pseudopneumoniae: report of three cases with an apparent hepatic or bile duct association. Infect Dis 8:636-639

Guiral S, Mitchell TJ, Martin B, Claverys JP (2005) Competence-programmed predation of noncompetent cells in the human pathogen Streptococcus pneumoniae: genetic requirements. PNAS 102:8710-8715

Hakenbeck R, Chhatwal S (2007) Molecular biology of streptococci. Horizon Bioscience, Norfolk

Harf-Monteil C, Granello C, Le Brun C, Monteil H, Riegel P (2006) Incidence and pathogenic effect of Streptococcus pseudopneumoniae. J Clin Microbiol 44:2240-2241

Himes PM, Allen SE, Hwang S, Bowers AA (2016) Production of sactipeptides in Escherichia coli: probing the substrate promiscuity of subtilosin A biosynthesis. ACS Chem Biol 11:1737-1744

Ikryannikova LN, Lapin KN, Malakhova MV, Filimonova AV, Ilina EN, Dubovickaya VA, Sidorenko SV, Govorun VM (2011) Misidentification of alphahemolytic streptococci by routine tests in clinical practice. Infect Gen Evol 11:1709-1715

Ikryannikova LN, Ischenko DS, Lominadze GG, Kanygina AV, Karpova IY, Kostryukova ES, Mayansky NA, Skvortsov VS, Ilina EN, Govorun VM (2016) The mystery of the fourth clone: comparative genomic analysis of four non-typeable Streptococcus pneumoniae strains with different susceptibilities to optochin. Eur J Clin Microbiol Infect Dis 35:119-130

Keith ER, Murdoch DR (2008) Antimicrobial susceptibility profile of Streptococcus pseudopneumoniae isolated from sputum. Antimicrob Agents Chemother 52:2998

Keith ER, Podmore RG, Anderson TP, Murdoch DR (2006) Characteristics of Streptococcus pseudopneumoniae isolated from purulent sputum samples. J Clin Microbiol 44:923-927

Kilian M, Poulsen K, Blomqvist T, Havarstein LS, Bek-Thomsen M, Tettelin H, Sørensen UBS (2008) Evolution of Streptococcus pneumoniae and its close commensal relatives. PLOS ONE 3:e2683

Kjos M, Miller E, Slager J, Lake FB, Gericke O, Roberts IS, Rozen DE, Veeninget JW (2016) Expression of Streptococcus pneumoniae bacteriocins is induced by antibiotics via regulatory interplay with the competence system. PLoS Pathog 12:e1005422

Law DJ, Dajani AS (1978) Interactions between Neisseria sicca and viridin B, a bacteriocin produced by Streptococcus mitis. Antimicrob Agents Chemother 13:473-478

Lohans CT, Vederas JC (2014) Structural characterization of thioether-bridged bacteriocins. J Antibiot 67:23-30

Lux T, Nuhn M, Hakenbeck R, Reichmann P (2007) Diversity of bacteriocins and activity spectrum in Streptococcus pneumoniae. J Bacteriol 189:7741-7751

Majchrzykiewicz J (2011) Bacteriocins of Streptococcus pneumoniae and its response to challenges by antimicrobial peptides. Dissertation, University of Groningen, The Netherlands
Maricic N, Anderson ES, Opipari AE, Emily AY, Dawid S (2016) Characterization of a multipeptide lantibiotic locus in Streptococcus pneumoniae. mBio 7:e01656-15

Miller SA, Dykes DD, Polesky HF (1988) A simple salting out procedure for extracting DNA from human nucleated cells. Nucleic Acids Res 16:1215

Miller EL, Abrudan MI, Roberts IS, Rozen DE (2016) Diverse ecological strategies are encoded by Streptococcus pneumoniae bacteriocin-like peptides. Genome Biol Evol 8:1072-1090

Mitchell J (2011) Streptococcus mitis: walking the line between commensalism and pathogenesis. Mol Oral Microbiol 26:89-98

Nes IF, Diep DB, Holo H (2007) Bacteriocin diversity in Streptococcus and Enterococcus. J Bacteriol 189:1189-1198

Perez AC, Pang B, King LB, Tan L, Murrah KA, Reimche JL, Wren JT, Richardson SH, Ghandi U, Swords WE (2014) Residence of Streptococcus pneumoniae and Moraxella catarrhalis within polymicrobial biofilm promotes antibiotic resistance and bacterial persistence in vivo. Pathog Dis 70:280-288

Pettigrew MM, Gent JF, Revai K, Patel JA, Chonmaitree T (2008) Microbial interactions during upper respiratory tract infections. Emerg Infect Dis 14:1584-1591

Santagati M, Scillato M, Patane F, Aiello C, Stefani S (2012) Bacteriocin-producing oral streptococci and inhibition of respiratory pathogens. FEMS Immunol Med Microbiol 65:23-31

Seitzer P, Huynh TA, Facciotti MT (2013) JContextExplorer: a tree-based approach to facilitate cross-species genomic context comparison. BMC Bioinform 14:18

Shahinas D, Thornton CS, Tamber GS, Arya G, Wong A, Jamieson FB, Ma JH, Alexander DC, Low DE, Pillaiet DR (2013) Comparative genomic analyses of Streptococcus pseudopneumoniae provide insight into virulence and commensalism dynamics. PLoS ONE 8:e65670

Shak JR, Vidal JE, Klugman KP (2013) Influence of bacterial interactions on pneumococcal colonization of the nasopharynx. Trends Microbiol 21:129-135

Son MR, Shchepetov MS, Adrian PV, Madhi SA, de Gouveia L, von Gottberg A, Klugman KP, Weiser JN, Dawid S (2011) Conserved mutations in the pneumococcal bacteriocin transporter gene, blpA, result in a complex population consisting of producers and cheaters. mBio 2:e00179-11

Teles C, Smith A, Ramage G, Lang S (2011) Identification of clinically relevant viridans group streptococci by phenotypic and genotypic analysis. Eur Clin Microbiol Infect Dis 30:243-250

van der Poll T, Opal SM (2009) Pathogenesis, treatment, and prevention of pneumococcal pneumonia. Lancet 374:1543-1556

Whatmore M, Efstratiou A, Pickerill AP, Broughton K, Woodard G, Sturgeon D, George R, Dowson CG (2000) Genetic relationships between clinical isolates of Streptococcus pneumoniae, Streptococcus oralis, and Streptococcus mitis: characterization of "atypical" pneumococci and organisms allied to S. mitis harboring S. pneumoniae virulence factor-encoding genes. Infect Immun 68:1374-1382

\section{Submit your manuscript to a SpringerOpen ${ }^{\odot}$ journal and benefit from:}

- Convenient online submission

- Rigorous peer review

- Open access: articles freely available online

- High visibility within the field

- Retaining the copyright to your article

Submit your next manuscript at $\boldsymbol{\nabla}$ springeropen.com 